\title{
The effect of infection with male-killing Rickettsia on the demography of female Adalia bipunctata L. (two spot ladybird)
}

\author{
GREGORY D. D. HURST*, EMMA L. PURVIS, JOHN J. SLOGGETT \& MICHAEL E. N. \\ MAJERUS \\ Department of Genetics, Downing Street, Cambridge CB2 3EH, U.K.
}

\begin{abstract}
Virulence of symbionts is considered to be the evolutionary product of conflicting selection pressures: maintenance of a live host from which to be transmitted, and maximization of the rate of transmission. This conflict is thought to be lessened when the symbiont is vertically transmitted, for here transmission depends on the maintenance of a healthy host. Past studies have confirmed this tenet, and have shown vertical transmission to select for decreased virulence. We here investigate the effects of the maternally inherited male-killing Rickettsia symbiont of Adalia bipunctata, the two spot ladybird, on the demography of the female host. Although no effect of infection on larval demography was observed, infection detrimentally affected the adult host, infected females showing both decreased fecundity and longevity in comparison to uninfected controls. These findings are discussed in relation to both the dynamics of the male-killing Rickettsia and the factors which affect the level of virulence of symbionts. Three hypotheses are put forward to explain why inherited symbionts are not avirulent in their female host.
\end{abstract}

Keywords: Adalia bipunctata, male-killing, Rickettsia, symbiosis, virulence.

\section{Introduction}

In southern England, seven per cent of female Adalia bipunctata (two spot ladybird) are host to a bacterium of the genus Rickettsia, which is transmitted to their offspring, and is lethal to male progeny (Hurst et al., 1992, 1993; Werren et al., 1994). The evolutionary cause of the male-killing behaviour of inherited microorganisms has recently come under scrutiny (Skinner, 1985; Werren, 1987; Hurst, 1991; Hurst \& Majerus, 1993). The bacteria usually reside in the cytoplasm of host cells, and are not transmitted by males, which therefore represent an evolutionary 'dead-end' for the bacterium. When male death occurs during embryogenesis, the male-killer also usually dies. This suicidal behaviour has been interpreted as evolving through kin selection (Skinner, 1985; Hurst, 1991). By killing male individuals, the bacterium may increase the lifetime reproductive success of sisters of the dead male host, which, by virtue of common descent, are likely to be infected. Two basic mechanisms have been proposed. First, the sisters' lifetime reproductive success may increase if male death increases the level of resources *Correspondence. available to them (Skinner, 1985; Hurst, 1991). Second, their lifetime reproductive success may increase by virtue of a decrease in the rate of inbreeding they suffer (Werren, 1987). There is evidence from a variety of hosts affected by male-killers that these advantages to male-killing do exist, although in a minority an advantage is not readily visible (Hurst \& Majerus, 1993). In $A$. bipunctata, two advantages to male-killing are evident. First, hatchlings (mainly females) consume dead sibling eggs (predominantly the dead males), gaining a resource advantage (G. D. D. Hurst et al., submitted). Second, females suffer a lower rate of cannibalism from their siblings, these being fewer in number (G. D. D. Hurst et al., in prep.).

Though maternally inherited symbionts have no long-term interest in being in a male host, their survival depends on the lifetime reproductive success of the female host (Ewald, 1987; Ewald \& Schubert, 1989), and both laboratory simulation using phage infecting E. coli (Bull et al., 1991) and comparative study of the virulence of nematodes infecting fig wasps (Herre, 1993) have confirmed that vertical transmission does select for lower symbiont virulence. This thesis led Smith \& Dunn (1991) to set out four characteristics 
that can be expected to be associated with vertically transmitted symbionts, as follows.

1 They should have no detrimental effects on the maternal host.

2 They should infect the germ-line in preference to other host tissues.

3 They should have no effect on female fecundity.

4 They should have no effect on the survival or growth of female offspring.

Vertical transmission, in producing a reduction in virulence, may in fact result in a net fitness benefit to female hosts which bear symbionts. It has been argued that symbionts can play a positive metabolic role and this may outweigh any virulence effects that they produce, resulting in the evolution of mutualism (Yamamura, 1993; Bermudes \& Joiner, 1993).

A significant level of virulence would cause the frequency of infected hosts to decrease. The bacterium would not be maintained unless this loss were compensated for by the combined effects of the creation of new hosts by horizontal transfer of the bacterium, and any advantages to infected females that result from male death. A positive effect on female hosts would, by comparison, suggest a decreased importance to these effects in respect of the maintenance of the bacterium. We here test the effects of the symbiont on the demography of the female host, in the absence of any benefits from killing males. The aim is to partition out any indirect demographic effects that arise from the male-killing action of the bacterium, from the direct effects associated with the level of virulence of the bacterium in the female host.

\section{Materials and methods}

Females from three separate Cambridge lines infected with the male-killing bacterium (T1-1-A, T1-3-F, L112) were outcrossed, and the demography of their progeny monitored in comparison to progeny from females which were normal with respect to sex ratio. In the case of lines T1-1-A and T1-3-F, where approximately a third of daughters of infected individuals did not inherit the symbiont, the progeny taken for comparison were derived from a 'revertant' (uninfected) sister mated to the same male as the biased sexratio female. In the case of line L1-12, which did not produce a significant number of revertant individuals, the comparator individuals were derived from two uninfected lines, maintained by outcrossing in the laboratory over the same number of generations as the sex-ratio lines.

Eggs from these females were collected and allowed to hatch. To control against any indirect effect of infection from the male-killing action of the bacterium in siblings, hatching larvae of both classes were prevented from cannibalizing unhatched eggs by removal of such eggs from clutches, using a fine needle. In order to obtain a good match between the environment of infected and uninfected individuals, a single neonate larva from a sex-ratio pair was placed in a petri dish with a neonate larva from the comparator strain, and the status of the resultant adults with respect to infection ascertained post-hoc. This pair of larvae was then fed on excess pea aphids, Acyrthosiphum pisum, under a constant $24 \mathrm{~h}$ light regime, until just before pupation. At this point they were separated into new dishes, so that the individual pupating first could be noted and isolated. Between six and 12 hours after emergence as adults, the members of the pair were weighed to the nearest milligram and sexed. If either of the pair was male, the pair was discarded. If both were female, then the individuals were placed in separate dishes and marked with the pair number and the subscript A or B, depending on order of emergence ( $A$ for first to emerge, $\mathrm{B}$ for second). These females were then fed three large aphids a day for eight days.

On the ninth day, each adult was placed in a new dish, allowed to mate once, and supplied thereafter with four large aphids per day. This level of food is enough to maintain a low rate of oviposition in normal laboratory lines without inducing high rates of cannibalism of the eggs by the adults. Pairs where either female refused to mate were discarded, to control against any cost of mating and mating refusal that might have been incurred, as has been observed in Drosophila (Fowler \& Partridge, 1989).

The eggs from these pairs were collected daily and counted, and the adult was placed in a new dish. Dishes were changed daily irrespective of the presence of an egg clutch, to prevent a positive feedback effect arising from the stimulating effect that placing females into clean dishes has on oviposition (Majerus et al., 1989). The two dishes containing the individual members of pairs were stacked together on the bench-top, with rotation of the dishes to control against possible effects of light on fecundity. Pairs where either individual failed to produce fertile eggs within the first 10 days were noted, discarded from the analysis, and their fertility assessed by mating them with other male partners. On the eighteenth day after emergence, the individuals were remated to decrease the chance that reductions in fertility rate might result from sperm depletion. The regime of aphids and dish-changing was maintained until the twenty-eighth day (20 days of egg laying), after which time the adults were fed daily on artificial food (see Majerus et al., 1989 for recipe). The date of death was recorded. 
The identification of the members of the pair with respect to infection status was ascertained post-hoc by observation of the hatch-rates of eggs produced by each individual. If this was ambiguous, larvae were reared to maturity and a sex ratio obtained. Post-hoc identification prevented any experimental bias in the provisioning of adults with aphids, the infected individual on the bench-top being anonymous.

In a separate investigation, the effect of the bacterium on host overwinter mortality was investigated. Neonate larvae were prevented from cannibalizing unhatched eggs and larvae were raised on a diet of excess $A$. pisum in groups of five siblings in $9 \mathrm{~cm}$ diameter petri dishes. Larvae from five sex-ratio and four normal matrilines were raised. Female adults were fed on excess aphids for 10 days after emergence, placed in clean $9 \mathrm{~cm}$ petri dishes, with paper screwed up to provide sheltered refuges, and placed in an unheated insectary. Overwintering commenced during the period between the end of September and the beginning of October. The mortality of the ladybirds was scored after 90 days.

\section{Results}

\section{Characterization of individuals as to status with respect to the sex-ratio trait}

Each pair could contain either a normal and an infected individual, or, if the individual from the sexratio pair was a revertant, two normal individuals. Analysis of egg hatch-rates allowed easy separation of the pairs of larvae with respect to infection status (Table 1). In one case (pair 5, not shown in the table), reversion had evidently occurred (one individual produced eggs with 92 per cent probability of hatching and a family which was 57 per cent male; the other, eggs with 82 per cent probability of hatching and a family which was 61 per cent male), and so this pair was discarded from the analysis. In the other cases, the egg hatch-rates clearly indicated which female of a pair was infected.

\section{The demographic effects of infection}

The effect of infection on the rate of development of larvae Infected and uninfected females showed similar likelihoods in respect of which emerged first (Table 2). In two cases, emergence of both individuals within a short period of time prevented classification as to order. No effect of infection on the rate of development of larvae could be discerned (sign test for difference from binomial: $n=29, P>0.90$ ).
The effect of infection on weight at emergence Neither the infected nor the normal female was regularly heavier on emergence (Table 3). The weight of the females, therefore, gave no indication of status with respect to infection (sign test for difference from binomial: $n=23, P>0.40$ ).

The effect of infection on oviposition rate Infection by the male-killing bacterium decreases the rate of egg production of female $A$. bipunctata (Table 4). The magnitude of the difference in the rates of egg production between the members of the pairs of females is proportional to the average fecundity of the pair (regression: $\quad F_{1,28}=77.9, \quad P<0.01$ ). There is no relationship between the proportionate $(\log )$ difference in fecundity and the average fecundity of a pair (regression: $F_{1,28}=0.06, \mathrm{P}>0.8$ ). This is, therefore, the best measure to use in analysis of the paired data. The mean logarithmic difference in daily egg production between pairs differs from zero $(t=-4.82,30$ d.f., $P<0.001)$.

The effect of infection on longevity Infected individuals tended to die before uninfected ones (Table 5). Longevity being extremely temperature-dependent, the data were analysed nonparametrically. Pairs were classified as displaying either a marginal or a large difference in survivorship. In this context, marginal is defined as being when the members of the pair died within 10 days of each other, and large as when 10 or more days separated the times of death of the pair. The data suggest that the longevity of uninfected individuals exceeds that of infected ones (sign test on which of the pair lives longer: $n=20, P<0.05$; sign test considering large differences only: $n=12, P<0.01$ ).

Effect of infection on overwinter mortality Any difference in the overwinter survivorship of infected and uninfected beetles is small. Whereas 32.9 per cent of females from male-killed lines survived the winter $(n=76), 40.3$ per cent of females from normal lines were alive at the end of the experiment $(n=57)$. There is no evidence that infection affects survivorship rate (contingency $\chi_{1}^{2}=0.77, \mathrm{NS}$ ).

\section{Discussion}

Infection with the male-killing bacterium, in the absence of any benefits accrued to female larvae from the male-killing action itself, produces changes in certain aspects of the demographic performance of the adult host. Infection decreases the rate of oviposition. It also produces a decrease in longevity. In contrast to the differences in the demographies of infected and uninfected adults, the demographies of infected and 
Table 1 Characterization of the members of pairs of Adalia bipunctata as to status with respect to infection with the male-killing Rickettsia

\begin{tabular}{|c|c|c|c|c|c|}
\hline \multirow[b]{3}{*}{ Pair } & \multirow{3}{*}{$\begin{array}{c}\text { Matriline } \\
\text { of sex-ratio } \\
\text { individual }\end{array}$} & \multicolumn{4}{|c|}{ Individual } \\
\hline & & \multicolumn{2}{|r|}{ Normal } & \multicolumn{2}{|r|}{ Infected } \\
\hline & & $\begin{array}{c}\text { Egg } \\
\text { hatch-rate }\end{array}$ & $\begin{array}{c}\text { Sex-ratio } \\
\text { (proportion male) }\end{array}$ & $\begin{array}{c}\text { Egg } \\
\text { hatch-rate }\end{array}$ & $\begin{array}{c}\text { Sex-ratio } \\
\text { (proportion male) }\end{array}$ \\
\hline 1 & T1-1-A & 0.81 & 0.40 & 0.39 & 0.18 \\
\hline 10 & T1-1-A & 0.90 & 0.57 & 0.37 & - \\
\hline 12 & T1-1-A & 0.85 & - & 0.39 & 0.00 \\
\hline 16 & L1-12 & 0.92 & - & 0.38 & - \\
\hline 19 & L1-12 & 0.94 & 0.40 & 0.48 & - \\
\hline 22 & T1-1-A & 0.96 & 0.63 & 0.31 & 0.08 \\
\hline 24 & L1-12 & 0.79 & - & 0.47 & 0.19 \\
\hline 32 & T1-1-A & 0.87 & 0.40 & 0.49 & 0.00 \\
\hline 37 & T1-3-F & 0.90 & - & 0.33 & 0.00 \\
\hline 43 & T1-3-F & 0.89 & - & 0.43 & - \\
\hline 45 & T1-3-F & 0.94 & - & 0.53 & - \\
\hline 48 & L1-12 & 0.89 & -- & 0.42 & - \\
\hline 50 & L1-12 & 0.93 & 0.73 & 0.46 & 0.00 \\
\hline 66 & L1-12 & 0.95 & -- & 0.43 & 0.00 \\
\hline 67 & L1-12 & 0.96 & - & 0.44 & - \\
\hline 68 & T1-3-F & 0.82 & - & 0.35 & 0.00 \\
\hline 69 & T1-3-F & 0.76 & 0.30 & 0.39 & 0.00 \\
\hline 70 & T1-3-F & 0.87 & - & 0.44 & - \\
\hline 71 & T1-3-F & 0.92 & 0.78 & 0.43 & - \\
\hline 77 & T1-1-A & 0.83 & 0.60 & 0.47 & 0.28 \\
\hline 85 & T1-3-F & 0.93 & - & 0.33 & - \\
\hline 88 & T1-3-F & 0.88 & - & 0.35 & - \\
\hline 91 & T1-3-F & 0.95 & - & 0.36 & 0.00 \\
\hline 92 & T1-3-F & 0.68 & 1.00 & 0.47 & - \\
\hline 93 & T1-3-F & 0.88 & 0.71 & 0.43 & 0.00 \\
\hline 96 & T1-3-F & 0.64 & 0.43 & 0.38 & - \\
\hline 97 & T1-3-F & 0.79 & - & 0.36 & 0.00 \\
\hline 105 & L1-12 & 0.93 & 1.00 & 0.47 & 0.23 \\
\hline 108 & L1-12 & 0.95 & 0.57 & 0.47 & 0.00 \\
\hline 109 & $\mathrm{~L} 1-12$ & 0.94 & - & 0.57 & - \\
\hline 111 & T1-1-A & 0.89 & - & 0.52 & 0.27 \\
\hline
\end{tabular}

Table 2 The emergence pattern of pairs comprising one normal and one sex-ratio $A$. bipunctata individual

\begin{tabular}{lccc}
\hline & \multicolumn{3}{c}{ Matriline of bacterium } \\
\cline { 2 - 4 } Emergence pattern & L1-12 & T1-1-A & T1-3-F \\
\hline Infected female first & 4 & 4 & 7 \\
Uninfected female first & 5 & 3 & 6 \\
Simultaneous & 1 & 0 & 1 \\
\hline
\end{tabular}

No evidence was shown for any effect of infection on development rate $(P>0.90)$.
Table 3 The comparative mass of concurrently reared individuals from sex-ratio and normal lines of $A$. bipunctata shortly after emergence as adults

\begin{tabular}{lccc}
\hline & \multicolumn{3}{c}{ Matriline of bacterium } \\
\cline { 2 - 4 } Heavier female & L1-12 & T1-1-A & T1-3-F \\
\hline Infected & 5 & 4 & 5 \\
Uninfected & 4 & 1 & 4 \\
Equal & 1 & 2 & 5 \\
\hline
\end{tabular}

No evidence was shown for any effect of infection on mass at emergence $(P>0.40)$. 
Table 4 The mean daily egg production of each member of the pairs of $A$. bipunctata, according to the strain of bacterium and infection status

\begin{tabular}{|c|c|c|c|}
\hline \multirow[b]{2}{*}{ Strain } & \multirow[b]{2}{*}{ Pair } & \multicolumn{2}{|c|}{ Mean daily egg production of } \\
\hline & & $\begin{array}{l}\text { Infected } \\
\text { female }\end{array}$ & $\begin{array}{l}\text { Uninfected } \\
\text { female }\end{array}$ \\
\hline \multirow[t]{7}{*}{ T1-1-A } & 1 & 11.05 & 17.40 \\
\hline & 10 & 12.80 & 12.10 \\
\hline & 12 & 10.25 & 14.70 \\
\hline & 22 & 16.60 & 24.20 \\
\hline & 32 & 15.00 & 26.30 \\
\hline & 77 & 24.60 & 19.95 \\
\hline & 111 & 13.00 & 19.15 \\
\hline \multirow[t]{10}{*}{ L1-12 } & 16 & 17.75 & 18.85 \\
\hline & 19 & 15.05 & 21.25 \\
\hline & 24 & 26.10 & 20.05 \\
\hline & 48 & 12.35 & 25.75 \\
\hline & 50 & 19.85 & 22.25 \\
\hline & 66 & 25.80 & 30.75 \\
\hline & 67 & 20.60 & 26.60 \\
\hline & 105 & 25.65 & 21.60 \\
\hline & 108 & 7.25 & 9.10 \\
\hline & 109 & 8.45 & 21.25 \\
\hline \multirow[t]{13}{*}{$\mathrm{T} 1-3-\mathrm{F}$} & 37 & 8.50 & 23.50 \\
\hline & 43 & 17.15 & 16.75 \\
\hline & 45 & 4.60 & 12.00 \\
\hline & 68 & 7.35 & 12.95 \\
\hline & 69 & 8.95 & 16.40 \\
\hline & 70 & 7.50 & 9.00 \\
\hline & 71 & 16.05 & 14.05 \\
\hline & 88 & 13.50 & 26.65 \\
\hline & 91 & 2.30 & 16.60 \\
\hline & 92 & 12.15 & 16.55 \\
\hline & 93 & 8.70 & 16.00 \\
\hline & 96 & 8.20 & 9.95 \\
\hline & 97 & 5.75 & 16.35 \\
\hline
\end{tabular}

Infected individuals have decreased fecundity $(P<0.001)$.

uninfected larvae appear to be very similar. The above experiments reveal infection to have little effect on two features of larval development: the rate of development of larvae, and the mass of adults at emergence.

The above conclusions are stated in the knowledge that there may be errors in the original classification of the members of each pair with respect to infection status. Such errors will be the classification of a normal individual as being infected on the basis of low egg hatch-rate. This will occur when the individual from the sex-ratio line is a revertant such that both individuals are uninfected, and one of the pair shows an aberrant low egg hatch-rate for some reason unrelated to male-killing. Because the comparison that is then being made is between two uninfected individuals ( $\mathrm{a}$
Table 5 The comparative longevity of infected and uninfected members of a pair

Matriline of bacterium

\begin{tabular}{lccc}
\cline { 2 - 4 } Longevity & L1-12 & T1-1-A & T1-3-F \\
\hline Infected $\gg$ uninfected & 0 & 0 & 1 \\
Infected > uninfected & 2 & 0 & 2 \\
Infected < uninfected & 2 & 1 & 1 \\
Infected « uninfected & 4 & 2 & 5 \\
\hline
\end{tabular}

$>,<$ : marginal differences in longevity; $\gg, \ll$ : large differences, as defined in text. Infected individuals have decreased longevity $(P<0.05)$.

comparison where the difference should have no regular direction), the presence of such errors increases the stringency of the statistical tests which suggest a direction to the data. This presumes that uninfected individuals producing eggs with low hatch-rate are healthy in all other aspects.

The lack of virulence of the bacterium in larvae is in accord with Smith \& Dunn (1991). The bacterium does, however, affect the fecundity and survivorship of the adult female host. This finding is consistent with the observed presence of the bacterium in haemocytes, a tissue other than the germline (Hurst, 1993), but not with Smith \& Dunn's (1991) theoretical expectation.

The finding of a positive level of virulence of this bacterium is, first and foremost, important in clarifying certain aspects of the dynamics of this bacterium. The bacterium produces a decrease in the mean lifetime reproductive output of the individuals it infects. The invasion of the bacterium must be associated with a combination of its indirect effects on the survivorship of female progeny through male-killing, and its rate of horizontal transfer. Beyond such an assertion, the study provokes two questions. First, to what extent is this level of virulence measured in the laboratory reflected in individuals in the field? Second, why do the observations of virulence of this and other male-killers not accord with the theoretical prediction of avirulence?

\section{Virulence and the demography of infected}

\section{A. bipunctata in the field}

The importance of virulence in the understanding of the evolution and maintenance of the male-killing Rickettsia depends crucially upon the effect of the bacterium on host demography in the field. To what extent do the decreases in oviposition rate and longevity measured in the laboratory, correspond to decreases in these variables in the field? The answer is that extrapolation is possible to some extent, but quantification of the effect is impossible. Most easily 
envisaged is the effect of the bacterium on fecundity. The advantages to daughters of infected females that result from the male-killing action of the bacterium act early in larval development, and will have little or no effect on the demography of the adult. It must, therefore, be expected that when aphid conditions in the field are similar to those in the experiment, the fecundity of infected individuals will be lower than that of uninfected ones. In the laboratory regime, fecundity levels were assessed for individuals supplied with amounts of food normally sufficient to produce one clutch of eggs each day (an excess of food was not used). When do such conditions occur? Past work on A. bipunctata on Vicia faba and Tilia $\times$ europa has suggested that oviposition starts before the aphid population has reached peak density: the adults will not be saturated with aphids (Banks, 1955; Hemptinne et al., 1992). The above experiments suggest that uninfected females would lay proportionately more eggs than infected ones during the early period of oviposition. Whether or not there exists a difference in fecundity later in the season, when aphids are more abundant, has yet to be ascertained. If it is the case that the bacterium reduces fecundity because it removes a fixed quantity of nutrients, then the bacterium may have a proportionately much smaller effect on the fecundity of its host when the host is saturated with nutrients. Clearly, this awaits test.

The ecological reality of the observed difference in survivorship is more difficult to ascertain. Adult $A$. bipunctata die in large numbers at two times: during winter and early summer (June until early July). During the latter period, food is usually abundant. If the above rationale is true (that the bacterium has a proportionately greater virulence during times when food is scarce), then the effect of the bacterium on host survivorship may be orders of magnitude higher when hosts are fed only artificial food (as in this experiment after the initial 28 day period), than would actually occur in the field during the summer. This is suggested in the light of two observations: that the artificial food is less nutritious than aphids ( $A$. bipunctata fails to reproduce if fed purely on this artificial food), and that the majority of individuals that survive the winter eventually die in the early summer when aphid populations are at their peak. The above experiment should be repeated at high aphid densities to investigate this prediction. Conditions during the other major period of high mortality, winter, are more similar to the conditions of the experiment in terms of nutrition. However, the experiment on overwinter mortality, although numerically suggesting a slight negative effect of infection, shows the overwinter survivorship of infected and uninfected females to be comparable.

\section{The evolution of virulence}

This study has shown that the male-killer in A. bipunctata is virulent in female hosts. This appears to be true of other male-lethal symbionts. Individual females from strains of Epiphyas postvittana bearing the malekilling agent produce eggs at only around half of the rate of individuals from uninfected lines (Geier et al., 1978). A decrease in the rate of egg production of approximately 40 per cent is seen in laboratory reared Spodoptera littoralis (Brimacombe, 1980). In a specifically controlled test comparing sex-ratio and normal lines of Drosophila bifasciata, Ikeda (1970) observed that infected females produced eggs $10-15$ per cent more slowly than uninfected counterparts. More anecdotally, Matsuka et al. (1975) note that infection of female Harmonia axyridis was associated with an increased incidence of sterility and a decrease in the rate of egg production. Laboratory investigation of the effect of infection of Drosophila willistoni with the male-killing spiroplasma, more ambiguously, shows infection to quicken larval development (probably advantageous), but also to increase sterility and decrease lifespan of adult females (Ebbert, 1991).

Virulence effects of inherited symbionts are observed more widely. Trichogramma wasps infected with the parthenogenesis-inducing Wolbachia have a lower potential fecundity in the laboratory than uninfected individuals (Stouthamer \& Luck, 1993). Female Drosophila simulans infected with the cytoplasmic incompatibility inducing Wolbachia have lower fitness than normal females (Hoffmann \& Turelli, 1988; Hoffmann et al., 1990). Similarly, Tribolium confusum infected with Wolbachia show a lower productivity than antibiotic-cured strains (Stevens \& Wade, 1990). The ectoparasitic tick of mammals, Dermacentor andersoni, tends to exhibit abnormalities in oviposition and egg development when infected with Rickettsia rickettsii (Burgdorfer \& Brinton, 1975). In contrast to these observations, no effect of Wolbachia infection on the rate of egg production was observed in Drosophila melanogaster (Hoffmann et al., 1994).

Although vertical transmission clearly does select for reduced virulence, it does not appear to always produce avirulence. This has obvious implications as a constraint on the evolution of mutualism from parasitic associations. But why is it that vertically transmitted micro-organisms remain virulent? Three possible explanations exist. First, the level of virulence may be a balance between selection for increased rate of transmission to the germline and selection for increased host fecundity. As May (1985) notes, avirulence is expected only if transmission and virulence are 
independent. If increases in symbiont number produce increases in transmission efficiency, then a low level of virulence will be expected to remain. In support of this notion, it is notable that in symbioses where the microorganism makes a positive metabolic contribution to the host, the host strictly controls the number and location of symbionts, through, among other mechanisms, enzymic degradation. This suggests that the micro-organism, in the absence of such repression, would multiply and have some degree of virulence. Second, the key assumption of clonality of the symbiont, inherent in models predicting selection for avirulence, may be untrue. If there is competition between symbiont strains, because of either superinfection by horizontal transmission or de novo production of novel strains by mutation, then the analysis of Ewald (1987) may be optimistic. Whether zygotes are ever heteroplasmic for symbiont strains is, however, unknown. Third, the symbiont may not have had enough time to evolve avirulence in these cases. If symbionts move between host species regularly, then they may never become perfectly adapted to a given host, and virulence will commonly be observed. An explanation of virulence based on evolutionary lag rests on the proviso that the infection of a particular symbiont strain in a particular species only has a short evolutionary history.

The data with which to test these hypotheses are not yet available. Clearly, studies which (i) examine the link between virulence and transmission efficiency, (ii) examine the degree of heteroplasmy for given symbionts, and (iii) examine the identity of symbionts in different host species, are required for full evaluation of the causes of virulence.

\section{Acknowledgements}

We thank Mr Roger Day and Mr Alan Feast for assistance, and an anonymous reviewer for comments on the manuscript. The work was carried out in a laboratory funded by the Wolfson Foundation. The work was funded by an SERC Quota award, and latterly by a Christ's College Junior Research Fellowship to Greg Hurst, and by an NERC grant (GR9/993) to Michael Majerus.

\section{References}

BANKS, C. J. 1955. An ecological study of Coccinellidae (Col.) associated with Aphis fabae Scop. on Vicia faba. Bull. ent. Res., 46, 561-587.

BERMUDES, D. AND JOINER, K. A. 1993. The role of parasites in generating evolutionary novelty. Parasitol. Today, 9, $458-463$.

BRIMACOMBE, L. C. 1980. All-female broods in field and laboratory populations of the Egyptian cotton leafworm,
Spodoptera littoralis (Boisduval) (Lepidoptera: Noctuidae). Bull. ent. Res., 70, 475-481.

BULL, J. J., MOLINEUX, I. J. AND RICE, W. R. 1991. Selection of benevolence in a host-parasite system. Evolution, 45, 875-882.

BURGDORFER, W. AND BRINTON, L. P. 1975. Mechanisms of transovariol infection of spotted fever rickettsiae in ticks. Ann. N.Y. Acad. Sci., 266, 61-72.

EBBERT, M. 1991. The interaction phenotype in the Drosophila willistoni - spiroplasma symbiosis. Evolution, 45, 971-988.

EWALD, P. W. 1987. Transmission modes and evolution of the parasitism-mutualism continuum. Ann. N.Y. Acad. Sci., 503, 295-306.

EWALD, P. W. AND SCHUBERT, J. 1989. Vertical and vector-borne transmission of insect endocytobionts and the evolution of benignity. In: Schwemmler, W. and Gassner, G. (eds) Insect Endocytobiosis: Morphology, Physiology, Genetics, Evolution, pp. 22-35. CRC Press, Boca Raton, FL.

FOWLER, K. AND PARTRIDGE, L. 1989. A cost to mating in female fruit flies. Nature, 338, 760-761.

GEIER, P. W., BRIESE, D. T. AND LEWIS, T. 1978. The light brown apple moth Epiphyas postvittana (Walker). 2. Uneven sex ratios and a condition contributing to them in the field. Aust. J. Ecol., 3, 467-488.

HEMPTINNE, J-L., DIXON, A. F. G. AND COFFIN, J. 1992. Attack strategies of ladybird beetles (Coccinellidae): factors shaping their numerical response. Oecologia, 90, 238-245.

HERRE, E. A. 1993. Population structure and the evolution of virulence in nematode parasites of fig wasps. Science, 259, 1442-1445.

HOFFMANN, A. A. AND TURELLI, M. 1988. Unidirectional incompatability in Drosophila simulans: inheritance, geographic variation and fitness effects. Genetics, 119, 435-444.

HOFFMAN, A. A., CLANCY, D. J. AND MERTON, E. 1994. Cytoplasmic incompatibility in Australian populations of Drosophila melanogaster. Genetics, 136, 993-999.

HOFFMANN, A. A., TURELLI, M. AND HARSHMAN, L. G. 1990. Factors affecting the distribution of cytoplasmic incompatiblity in Drosophila simulans. Genetics, 126, 933-948.

HURST, G. D. D. 1993. Studies of Biased Sex-ratios in Adalia bipunctata L. Unpublished $\mathrm{PhD}$ Thesis, University of Cambridge, U.K.

HURST, G. D. D. AND MAJERUS, M. E. N. 1993. Why do maternally inherited microorganisms kill males? Heredity, 71, 81-95.

HURST, G. D. D., MAJERUS, M. E. N. AND WALKER, L. E. 1992. Cytoplasmic male-killing elements in Adalia bipunctata (Linnaeus) (Coleoptera: Coccinellidae). Heredity, 69, 84-91.

HURST, G. D. D., MAJERUS, M. E. N. AND WALKER, L. E. 1993. The importance of cytoplasmic male killing elements in natural populations of the two spot ladybird, Adalia bipunctata (Linnaeus) (Coleoptera:Coccinellidae). Biol. J. Linn. Soc., 49, 195-202.

HURST, L. D. 1991. The incidences and evolution of cytoplasmic male killers. Proc. R. Soc. Lond. B, 244, 91-99.

IKEDA, H. 1970. The cytoplasmically-inherited 'sex-ratio' condition in natural and experimental populations of Drosophila bifasciata. Genetics, 65, 311-333. 
MAJERUS, M. E. N., KEARNS, P. W. E., FORGE, H. AND IRELAND, H. 1989. Ladybirds as teaching aids. I. Collecting and culturing. J. Biol. Ed., 23, 187-192.

MATSUKA, M., HASHI, H. AND OKADA, I. 1975. Abnormal sex-ratio found in the lady beetle, Harmonia axyridis Pallas (Coleoptera: Coccinellidae). Appl. Ent. Zool., 10, 84-89.

MAY, R. M. 1985. Host-parasite associations: their population biology and population genetics. In: Rollinson, D. and Anderson, R. M. (eds) Ecology and Genetics of Host-Parasite Interactions, pp. 243-262. Academic Press, London.

SKINNER, s. w. 1985. Son-killer: a third extrachromosomal factor affecting the sex ratio in the parasitoid wasp, Nasonia (=Mormoniella) vitripennis. Genetics, 109, 745-759.

SMITH, J. E. AND DUNN, A. M. 1991. Transovariol transmission. Parasitol. Today, 7, 146-148.
STEVENS, L. AND WADE, M. J. 1990. Cytoplasmically inherited reproductive incompatibility in Tribolium flour beetles: the rate of spread and effect on population size. Genetics, 124, 367-372.

STOUTHAMER, R. AND LUCK, R. F. 1993. Influence of microbeassociated parthenogenesis on the fecundity of Trichogramma deion and T. pretiosum. Ent. Exp. Appl., 67, 183-192.

WERREN, J. H. 1987. The coevolution of autosomal and cytoplasmic sex ratio factors. J. Theor. Biol., 124, 317-334.

WERREN, J. H., HURST, G. D. D., ZHANG, W., BREEUWER, J. A. J., STOUTHAMER, R. AND MAJERUS, M. E. N. 1994. Rickettsial relative associated with male-killing in the ladybird beetle (Adalia bipunctata). J. Bacteriol., 176, 388-394.

YAMAMURA, N. 1993. Vertical transmission and evolution of mutualism from parasitism. Theor. Pop. Biol., 44, 95-109. 